\title{
HIV prevalence and associated risk factors among rural pregnant women in North Central Nigeria
}

\author{
Christian Isichei ${ }^{1,}$ *, Pamela Brown ${ }^{2}$, Mercy Isichei ${ }^{3}$, Jean $\mathrm{Njab}^{4}$, Tinuade Oyebode ${ }^{5}$, \\ Prosper Okonkwo ${ }^{6}$ \\ ${ }^{1}$ Department of Chemical Pathology, Faculty of Medical Sciences, University of Jos, /Faith Alive Foundation, Jos, Nigeria \\ ${ }^{2}$ New Mexico department of Corrections, Santa Fe, USA \\ ${ }^{3}$ Department of Surgery, Faculty of Medical Sciences, University of Jos, /Faith Alive Foundation, Jos, Nigeria \\ ${ }^{4}$ Department of Chemical Pathology, Bingham University, Jos Campus, Nigeria \\ ${ }^{5}$ Department of Obstetrics and Gynaecology, Faculty of Medical Sciences, University of Jos, Jos, Nigeria \\ ${ }^{6}$ AIDS Prevention Initiative in Nigeria (APIN) Ltd, Abuja, Nigeria
}

Email address:

Christian_isichei@yahoo.com (C. Isichei)

\section{To cite this article:}

Christian Isichei, Pamela Brown, Mercy Isichei, Jean Njab, Tinuade Oyebode, Prosper Okonkwo. HIV Prevalence and Associated Risk Factors among Rural Pregnant Women in North Central Nigeria. American Journal of Health Research. Vol. 3, No. 1, 2015 , pp. $18-23$. doi: 10.11648/j.ajhr.20150301.14

\begin{abstract}
Aim: To determine the prevalence of HIV infection and associated risk factors among rural pregnant women in Plateau state, Nigeria. Study Design: The study involved a cross-sectional study of pregnant rural women in antenatal clinics (ANCs) in five (5) rural villages of Mangu Local Government area of Plateau State, North Central Nigeria. Methodology: A total of 248 pregnant women with mean age of 26 years were recruited through a random sampling method during ANCs with pre and post counseling initiated and a structured survey questionnaire used. Venous blood samples were collected using needles and syringes, thereafter transported to a central point at Gindiri, centrifuged and serum sent to Plateau Specialist Hospital virology laboratory for HIV testing. Results: Participants with less than six (6) months planned postpartum sexual abstinence(cultural to abstain from Sexual Intercourse during pregnancy) were 8 times significantly more likely (OR 8.2; 95\% CI $1.4,42.0)$ to be infected compared with those who observed more than six (6) months planned postpartum abstinence. Also, women from polygamous marriages had a five-fold greater and significantly odds (OR 5.36; 95\%CI 1.3, 24.5) of being HIV positive compared to women from monogamous marriages. Furthermore, parous women were 4 times significantly more likely (OR 4.66; 95\%CI 1.1,20.0) to be infected than nulliparous women. Previous exposure to malaria and educational status were not significantly associated with HIV infection. Conclusion: HIV prevalence was $3.2 \%(95 \% \mathrm{CI} ; 1.5-6.5)$ comparable to Nigerian's current overall prevalence rate and high lights need to eliminate preventable risk factors and relevance of male involvement in HIV prevention especially during pregnancy including ANCs, Care, Treatment and Support. There was higher rate of HIV infection among women who did not abstain from sexual intercourse during pregnancy suggesting multiple partnerships and need for marital faithfulness especially from the men during pregnancy.
\end{abstract}

Keywords: HIV, Risk Factors, Rural, Prevalence and Male Involvement

\section{Introduction}

Globally, HIV/AIDS has emerged the leading cause of mortality among women of reproductive age and contributes a great deal to the death of infants and children ${ }^{1}$. Over the decades, the epidemic, once dominated by infected males has become progressively feminized and each day, an estimated 1000 children under the age of 15 acquire Human Immunodeficiency virus (HIV) infection ${ }^{2}$.The high rates of
HIV infection and its consequences is a socio economic challenge for most developing countries, with the potential to reverse health and developmental gains as reflected by indices such as, life expectancy at birth, infant and maternal mortality rate among others ${ }^{3}$.

In Sub Saharan Africa, an estimated 2.9 million children were living with HIV /AIDS in 2012 and about 260,000 children were newly infected with HIV. Over $90 \%$ of these infections occur through mother-to-child transmission 
$(\mathrm{MTCT})^{4}$. It is pertinent to note that without interventions, the rate of HIV MTCT ranges from $25 \%$ to $40 \%$, however with effective interventions, HIV MTCT rates have been reduced below $2 \%{ }^{4}$ and virtually eliminated in most developed countries, while many developing countries including Nigeria, still record high pediatrics HIV transmission rates ${ }^{5-7}$.

With an estimated HIV prevalence of $3.4 \%{ }^{8}$, Nigeria has the second largest HIV burden in the world with a generalized HIV epidemic driven by low risk perception, multiple partnerships, trans-generational and transactional sex, unabated stigmatization and discrimination, poor management and access to TB/STI services, as well as poverty and gender based vulnerabilities. Two series of integrated bio-behavioral sentinel surveys (IBBSS) have shown that female sex workers (FSW), men who have sex with men (MSM) and people who inject drugs (PWID) are bridging populations with prevalence as high as $27.4 \%, 17.2 \%$ and $4.2 \%$ respectively ${ }^{9}$. About three million people live with HIV and AIDS in Nigeria, and HIV prevalence estimates are higher among women $(3.5 \%)$ than men $(3.3 \%)$ and slightly higher in semi-urban areas $(3.6 \%)$ compared with the urban $(3.2 \%)^{10}$.Though, the country has experienced a steady decline in trend of HIV prevalence among women attending ante natal clinics ANCs from 5.8\% in 2001 through 5.0\% in 2003 , to $4.4 \%$ in 2005 and 4.1 in 2010 , most of these studies have generally been conducted in urban or semi-urban areas and have appeared too generic to address the peculiarities and vulnerabilities of North Central Nigeria, let alone rural areas in Plateau state. 2014 study by authors and unpublished show a $1.41 \%$ in urban areas and state prevalence down from $7.7 \%$ to $2.2 \%$.

There is a dearth of data about HIV prevalence estimates and associated risk factors among pregnant women in rural areas. Recent demographic and health survey in Nigeria estimated that pregnant women in rural areas have on average two children more than urban women and fertility differentials and HIV/AIDS comprehensive knowledge are significantly noticeable ${ }^{11}$.We primarily estimated the risk factors especially how long sexual intercourse was laid and secondarily the prevalence of HIV among rural pregnant women to provide evidence for effective prevention of HIVMTCT in Plateau state, North Central Nigeria.

\section{Materials and Methods}

\subsection{Design}

We conducted a cross-sectional study to estimate the prevalence of HIV and associated risk factors among rural pregnant women in ANCs in five (5) rural villages in the Mangu Local Government area of Plateau State, North Central Nigeria. In the context of this study, rural areas were defined as villages and communities living and earning a livelihood far (at least 100 kilometers) from the main city and capital, Jos and a state of greater than 3 million population. The study was carried out over a 6 -week period (June and
July 2008). All pregnant women attending the ANCs were eligible for the study, except those who opted out. Ethical approval for the study was obtained from the Ethical Committee of Jos University Teaching Hospital (JUTH) Plateau State and the Mangu Local Government health authority. Participants' consent were duly obtained after explanations in the language best understood by them. All logistics were at the headquarters of research unit of Faith Alive Foundation, Jos, Nigeria.

We adapted a structured survey questionnaire used in a similar study among Rwandan women ${ }^{12}$. This survey tool was modified to elicit information about local cultural practices including polygamy, breastfeeding; postpartum self reported after-the-fact sexual abstinence and circumcision, in addition to knowledge, attitude, perception about HIV/AIDS and prevention methods. The questionnaire was piloted and administered in a face to face interview by trained health workers again in the local languages best understood by participants.

\subsection{Selection of Participants and Laboratory HIV Testing}

Participants were recruited in a simple random sampling method during antenatal clinics days and no exclusion criterion was used, except for those who did not want to participate in the study. A total of 248 women participated in the study, enough to achieve $3 \%$ study precision at $95 \%$ confidence interval and all had Voluntary Counseling and Testing pre and post testing. A unique identification number was assigned to each participant's questionnaire and linked to blood specimen in a confidential log register. Venous blood samples collected using needles and syringes were carefully transported and processed into sera at Gindiri site laboratory with all biosafety/universal precautions and analyzed by Enzyme linked Immunosorbent Assay (ELISA) at the Robert Gallo virology laboratory of Plateau Specialist Hospital in Jos. Seropositive samples were confirmed by Western Blot. All HIV-positive women received post-test counseling and were enrolled for Care, Treatment and Support at Faith Alive Foundation and PMTCT Center, Jos- one of the earliest treatment sites for HIV in Nigeria courtesy of one of the authors from New Mexico and later with The President's Emergency Plan For AIDS Relief (PEPFAR) grant in 2004.

\subsection{Data Capture and Analysis}

Data were captured and analyzed on Epi Info 6.04. Cross tabulations were used to generate descriptive statistics including frequency distribution, percentages and Fisher's exact odds ratios at $95 \%$ confidence limits with $5 \%$ probability level of significance.

\section{Results}

\subsection{Geographic Distribution of Participants}

Total of 248 pregnant women participated in this study with $8(3.2 \%)$ participants testing positive for HIV infection. Majority $(66 \%)$ came from Mangu ( $9^{\circ} 31$ North, $9.10^{\circ}$ East) 
community 85 kilometers from Jos the capital of Plateau state. One quarter $(25 \%)$ were recruited from Gindiri $\left(9^{\circ} 36\right.$ North, $9^{\circ} 14$ East) community about 101 kilometers from Jos, while a few $(9 \%)$ were from Ampang-West (110 kilometers from Jos, $9^{\circ} 06$ West $/ 9.51^{\circ}$ North).

\subsection{Demographic Characteristics of Participants and HIV Prevalence Estimate (Table 1)}

A total of 248 pregnant women with a mean age of 26 years $(\mathrm{SD}, 6)$ participated in this study (Table 1). Majority $(75 \%)$ had a minimum of primary school education and almost all $(98 \%)$ were married. Equal percent $(36 \%)$ were farmers or petty traders and less than a third (28\%) were civil/public servants. Almost all (96\%) had a monthly income of less than NGN 10,000 $(\approx \$ 60.0)$ and majority $(75 \%)$ were Christians and the remainder were percentage of other religions, Plateau State being predominantly a Christian State. HIV prevalence as stated was $3.2 \%(95 \% \mathrm{CI} ; 1.5-6.5)$.

Table 1. Socio-demographic characteristics of participants and HIV prevalence estimate.

\begin{tabular}{|c|c|c|}
\hline Variables & Frequency (n) & Percentage (\%) \\
\hline \multicolumn{3}{|l|}{ Education (years) } \\
\hline None & 61 & 25 \\
\hline Primary & 95 & 39 \\
\hline Secondary & 84 & 34 \\
\hline$>$ Secondary & 4 & 2 \\
\hline \multicolumn{3}{|l|}{ Marital status } \\
\hline Never married & 2 & 1 \\
\hline Married & 241 & 98 \\
\hline Divorced/widowed & 1 & 1 \\
\hline \multicolumn{3}{|l|}{ Occupation } \\
\hline Farmers & 88 & 36 \\
\hline Petty Traders & 87 & 36 \\
\hline Civil servants & 69 & 28 \\
\hline \multicolumn{3}{|c|}{ Income per month (Naira) } \\
\hline$<\mathrm{N} 1000$ & 171 & 76 \\
\hline N1000-5000 & 44 & 19 \\
\hline N5001-10, 000 & 3 & 1 \\
\hline$>\mathrm{N} 10,000$ & 8 & 4 \\
\hline \multicolumn{3}{|l|}{ Religion } \\
\hline Christian & 183 & 75 \\
\hline Muslim & 49 & 20 \\
\hline Other Religions & 11 & 5 \\
\hline \multicolumn{3}{|c|}{ Mean monthly income } \\
\hline Naira & N 1009 & \\
\hline$(\mathrm{USD})^{*}$ & $(\$ 6.3)$ & \\
\hline Mean Age (years) & $25.8(\mathrm{SD}, 6)$ & \\
\hline HIV Positive & 8 & 3.2 \\
\hline
\end{tabular}

$* \$ 1=168 \mathrm{NGN}$

\subsection{HIV/STI Knowledge Risk Assessment (Table 2)}

The majority $(82 \%)$ of research study participants had heard of HIV/AIDS and more than half $(68 \%)$ were aware of sexually transmitted infections STIs (Table 2). In addition, about $46 \%$ and $36 \%$ of participants had misconception about HIV transmission by kissing and sharing utensils respectively. The majority knew that HIV could be transmitted by sharing contaminated needles $((80 \%)$ and unprotected sexual intercourse $(82 \%)$ with an infected partner. Eighty percent $(80 \%)$ were willing to try new ways of preventing HIV.

Table 2. HIV/AIDS Knowledge Risk Assessment among Participants.

\begin{tabular}{|c|c|c|c|c|}
\hline Variables & $\mathbf{n}$ & $\%$ & $\mathbf{X}^{2}$ & P-value \\
\hline \multicolumn{5}{|l|}{ Heard of HIV } \\
\hline Yes & 97 & 40 & 19.8 & $0.001 *$ \\
\hline No & 146 & 60 & & \\
\hline \multicolumn{5}{|l|}{ Heard of AIDS } \\
\hline Yes & 200 & 82 & 3.11 & 0.08 \\
\hline No & 44 & 18 & & \\
\hline \multicolumn{5}{|l|}{ Heard of STDs } \\
\hline Yes & 165 & 68 & 7.1 & $0.007^{*}$ \\
\hline No & 77 & 32 & & \\
\hline \multicolumn{5}{|c|}{ Tell HIV by looking } \\
\hline Yes & 64 & 26 & 0.63 & 0.7 \\
\hline No & 169 & 70 & & \\
\hline Don’t Know & 9 & 4 & & \\
\hline \multicolumn{5}{|c|}{ Get HIV by kissing } \\
\hline Yes & 84 & 35 & 4.93 & 0.08 \\
\hline No & 127 & 54 & & \\
\hline Don’t Know & 26 & 11 & & \\
\hline \multicolumn{5}{|c|}{ Get HIV sharing utensils } \\
\hline Yes & 63 & 26 & 4.56 & 0.10 \\
\hline No & 153 & 64 & & \\
\hline Don’t Know & 24 & 10 & & \\
\hline \multicolumn{5}{|c|}{ Get HIV sharing needles } \\
\hline Yes & 191 & 80 & 3.06 & 0.2 \\
\hline No & 37 & 15 & & \\
\hline Don't Know & 12 & 5 & & \\
\hline \multicolumn{5}{|c|}{$\begin{array}{l}\text { Get HIV through sex with } \\
\text { infected partner }\end{array}$} \\
\hline Yes & 195 & 82 & 4.97 & 0.08 \\
\hline No & 31 & 13 & & \\
\hline Don't Know & 12 & 5 & & \\
\hline \multicolumn{5}{|c|}{$\begin{array}{l}\text { Willing to try new way to } \\
\text { prevent }\end{array}$} \\
\hline Yes & 193 & 80 & 4.75 & $0.03 *$ \\
\hline No & 46 & 19 & & \\
\hline
\end{tabular}

$* \mathrm{p}<0.05$ (statistically significant)

\subsection{Participants Risk Factors Associated with HIV (Table 3)}

Participants with less than six (6) months planned postpartum sexual abstinence were 8 times significantly more likely (OR 8.2; 95\% CI 1.4, 42.0)to be infected compared with those who observed more than six (6) months planned postpartum abstinence (Table 3). Also, women from polygamous marriages had a five-fold greater and significantly odds (OR 5.36; 95\%CI 1.3, 24.5) of being positive HIV compared with women from monogamous marriages. Furthermore, parous women were 4 times significantly more likely (OR 4.66; 95\%CI 1.1, 20.0) to be infected than nulliparous. Those who did not abstain at all 
had higher rate of HIV infection suggesting multiple partnerships and need for marital faithfulness especially from male partners. Previous exposure to malaria and educational status were not significantly associated with HIV infection.

Table 3. Participants Risk Factors Associated HIV.

\begin{tabular}{|c|c|c|c|c|c|c|}
\hline & \multicolumn{2}{|c|}{ HIV-positive $(n=8)$} & \multicolumn{2}{|c|}{ HIV-negative $(n=240)$} & \multirow[t]{2}{*}{ OR, p } & \multirow[t]{2}{*}{$95 \%$ CI } \\
\hline & $\mathrm{n}$ & $\%$ & $\mathrm{n}$ & $\%$ & & \\
\hline \multicolumn{7}{|c|}{ Education } \\
\hline$>6$ yrs. & 6 & 75 & 85 & 36 & $5.36 ; 0.05$ & $(1.1,27.2)$ \\
\hline$\leq$ 6yrs. & 2 & 25 & 152 & 64 & & \\
\hline \multicolumn{7}{|c|}{ Polygamy } \\
\hline Yes & 4 & 50 & 36 & 19 & $5.36 ; 0.03 *$ & $(1.3,24.5)$ \\
\hline No & 4 & 50 & 193 & 81 & & \\
\hline \multicolumn{7}{|c|}{ Prior pregnancy } \\
\hline Yes & 5 & 63 & 63 & 26 & $4.66 ; 0.04 *$ & $(1.1,20.0)$ \\
\hline No & 3 & 37 & 176 & 74 & & \\
\hline \multicolumn{7}{|c|}{ Self Planned postpartum sexual abstinence } \\
\hline$<6$ mo. & 6 & 75 & 54 & 27 & $8.22 ; 0.001 *$ & $(1.6,42.0)$ \\
\hline$\geq 6 \mathrm{mo}$. & 2 & 25 & 148 & 73 & & \\
\hline \multicolumn{7}{|c|}{ Malaria past 3 years } \\
\hline Yes & 7 & 88 & 123 & 51 & $6.60 ; 0.07$ & $(0.8,54.5)$ \\
\hline No & 1 & 12 & 116 & 49 & & \\
\hline
\end{tabular}

$\mathrm{OR}=$ Odd ratio, $\mathrm{CI}=$ confidence interval, $* \mathrm{p}<0.05$

\section{Discussion}

In most rural areas of the developing world including SubSahara Africa in general and Nigeria in particular, women play a key role in running households, making major contributions to agricultural production and sustaining the socio-economic life of villages and communities, through a network of formal and informal income generating activities. However, the key role in these activities is increasingly threatened by the HIV/AIDS scourge in most Sub-Saharan countries and Nigeria is not spared.

We found a prevalence of 3.2\% in this rural area (ManguGindiri-Ampang axes), approximately 85 - 110 kilometers from Jos, the capital of Plateau State, North Central Nigeria. Though this prevalence estimate was lower than the $3.6 \%$ reported in other rural areas in $\mathrm{Nigeria}^{13}$, it is pertinent to note that this estimate is close to the $3.4 \%$ reported as current national HIV prevalence among the general population thus, the call for collective action.

Similar studies across the continent have reported increase rate in HIV prevalence among rural women. In Central Africa, prevalence rates in rural areas increased from $2.2 \%$ in 1991 to $3.6 \%$ in $2003^{14}$. In Southern Africa, prevalence estimates varied from $2.3 \%$ to $17 \%$ among rural women ${ }^{15}$, while recent prevalence rate in Eastern Africa was up to $19.1 \%{ }^{16}$. In Asia, though a meta-analysis reported prevalence estimates far lower (less than 1\%) than those found in Sub-Sahara Africa, estimates among rural women were three-fold significantly greater than those in male counterpart. Studies in the USA have also shown relatively elevated prevalence estimates of about $5.8 \%$ in non-metropolitan areas ${ }^{17}$.
The disparities in HIV prevalence estimates in rural areas across the world are strongly dependent on the operational definition of "rural areas". In the context of this study, findings in sub-Sahara Africa may present the same comparative ecology, thus HIV infection was eight times significantly associated with short (less than 6 months)selfplanned postpartum sexual abstinence, five times significantly associated with polygamous marital status and four times with parity. In Sub-Sahara Africa rural ecology in general and Nigeria in particular, these three factors are essentially male dominant determinants, with cultural and faith-based correlates. The length of postpartum sexual abstinence (PSA) in marriage is often determined by the man particularly in rural areas. The decision to bring in another woman or concubine in a marriage is often man driven. Parity is also influenced by the man. In this study, almost all (98\%) of participants were married and most (95\%) were faith-based (Christians or Muslims), suggesting that husbands had a great influence on both PSA and parity.

Our data also showed that majority (82\%) knew that HIV can be contracted through unprotected sex with an infected partner and up to $80 \%$ were willing to try new ways of prevention after proper education. Consequently most married women in rural areas may be willing to explore lifesaving sexual and reproductive skills like condoms, pill contraceptive and microbicides with the permission of their husbands. In some communities, Christianity and Islam do not give the woman the right to access lifesaving sexual and reproductive skills without the permission of the husband or ability to negotiate sex. Therefore the call for male involvement in HIV/AIDS Prevention, Care, Treatment and Support has 
become imperative and the terminology should be PPTCTPrevention Parent To Child Transmission of HIV rather than Prevention Mother To Child Transmission (PMTCT) of HIV.

Several studies strongly suggested that male gender and faith-based dominance significantly limit women access to lifesaving sexual and reproductive skills in most developing countries. Ijadunola et al. ${ }^{18}$ found religion as a major barrier to male involvement in sexual and reproductive health in Nigeria. In Malawi, Shattuck et al., ${ }^{19}$ showed that male involvement can lead to contraceptive uptake through the pathway of increased spousal communication. Furthermore, Hartmann et al., ${ }^{20}$ demonstrated that male involvement improves access to sexual and reproductive health information, while Ademola et al., ${ }^{21}$ established that providing men with information and involving them in counseling sessions can help them to be more supportive of contraceptive use and more aware of the concept of shared decision making. In the light of the above, engaging men in sexual and reproductive health programmes especially during antenatal and perinatal clinics may become a lifesaving strategy for the prevention of HIV and other sexually transmitted infections that threaten the emancipation of women in rural areas in North Central Nigeria and Plateau state in particular.

\section{Conclusion}

Our findings suggest that HIV prevalence among pregnant women closely reflect general population based HIV burden in Nigeria hence the application for Nigerian's sentinel surveys especially as they portray the sexually active group. The impact of HIV prevention interventions including minimizing the associated risk factors including literacy for pregnant women in rural areas will always require a significant male involvement.

\section{Recommendation}

Therefore HIV prevention programmes targeting rural women in Nigeria should have a strong male component and a faith-based strategy for maximum impact. This is a clarion call for government officials at all levels; development partners, religious organizations, the organized private sector, community and traditional leaders.

\section{Acknowledgment}

We acknowledge the role of Marc Bulterys of CDC, Atlanta who with the corresponding author obtained the World AIDS Foundation grant for this work, Sally Barlow (New Mexico, USA) and David Atu of Medical Microbiology Department, Jos University Teaching Hospital for their great assistance/support with this work. APIN (Nig) Ltd is acknowledged as major stabilizing factor of comprehensive HIV/AIDS services at Faith Alive Foundation. Lastly, Dr Arthur Ammann discoverer of Paediatric AIDS for always being there for us.

\section{References}

[1] World Health Organization (WHO), 2010. PMTCT Strategic Vision 2010-2015, preventing mother-to-child transmission of HIV to reach the UNGASS and Millennium Development Goals.

[2] UNAIDS (2010) Global report: UNAIDS report on the global AIDS epidemic, 15 - 17.

[3] UNAIDS report on the global AIDS epidemic 2013, 7-8

[4] UNAIDS report on the global AIDS epidemic. 2010. Joint United Nations program on HIV/AIDS.

[5] Burr C K, Lampe M A, Corle S, Margolin FS, Abresh C and Clark J, 2007. An end to perinatal HIV: Success in the US requires ongoing and innovative efforts that should expand globally. J Public Health Policy; 28:249-60.

[6] Royal College of Obstetricians and Gynaecologists,2004. Management of HIV in pregnancy. Guideline No. 39. London: RCOG.

[7] Mofenson L M, 2010. Prevention in neglected subpopulations: Prevention of mother-to-child transmission of HIV infection. Clin Infect Dis; 50Suppl 3:S130-48.

[8] Federal Ministry of Health. National Reproductive and Health Survey Plus (NARHS PLUS), 2012. 8 - 11

[9] Federal Ministry of Health. Integrated Biological and Behavioral Sentinel Survey (IBBSS), 2010. 15 - 22

[10] Nigeria Demographic and Health Survey (2008 NDHS). National Bureau of Statistics

[11] Nigerian prevention of mother to child transmission of human immunodeficiency virus program: The journey so far (2013).Journal of HIV \& Human Reproduction. IP: 41.217.204.210

[12] Republic of Rwanda Ministry of Health. Behavioral and Biological Surveillance Survey Female Sex Workers, Rwanda 2006. Kigali: Republic of Rwanda Ministry of Health.

[13] Federal Ministry of Health. National Reproductive and Health Survey Plus (NARHS PLUS), 2012. 10 - 17

[14] Chao A, Bulterys M and Musanganire F, 1994. Risk factors associated with prevalent HIV-1 infection among pregnant women in Rwanda. Int J Epidem, 23:371-380.

[15] Mnyika K S., Klepp K I., Kvale G., Ole-King'ori N., 1996. AcquirImmune Defic Syndr Hum Retroviral. Apr 15; 11(5):484-91.Risk factors for HIV-1 infection among women in the Arusha region of Tanzania.

[16] Foglia G., Sateren W. B., Renzullo P. O., Bautista, C. T., Langat, C. T. Wasunna M. K., Singer, D. E., Scott, P. T., Robb, M. L. and Birx, D. L. 2008. High prevalence of HIV infection among rural tea plantation residents in Kericho, Kenya. EpidemiolInfect.136(5):694-702.

[17] Forney, M. A., and Holloway, T. (1990). Crack, syphilis, and AIDS: The triple threat to rural Georgia. GAFP Journal (2), 5-6.

[18] Macellina Y I, Titilayo C A, Kayode T I, Olusegun T A,Olapeju A E, and Funmilola M O, 2010. Male Involvement in Family Planning Decision Making in Ile-Ife,Osun State, Nigeria .Afr J Reprod Health; 14[4]: 45-52. 
[19] Shattuck D, Kerner B, Gilles K, Hartmann M, Ng'ombe T, and Guest G. 2011. "Encouraging contraceptive uptake by motivating men to communicate about family planning: the Malawi Male Motivator project," The American Journal of Public Health, vol. 101, no. 6, pp. 1089-1095,

[20] Hartmann M, Gilles K, Shattuck D, Kerner B, and Guest G,
2012. "Changes in couples' communication as a result of a male involvement family planning intervention," Journal of Health Communication, vol. 17, no. 7, pp. 802-819.

[21] Ademola A, Philomena O, and Elizabeth E. 2014.Male Involvement in Family Planning: Challenges and Way Forward. International Journal of Population Research.7-12 